\title{
DOSES DE POTÁSSIO NA PRODUÇÃo DE MUdAS DE UVAIA
}

\author{
SOUZA, Henrique Antunes ${ }^{88}$ \\ MENDONÇA, Vander ${ }^{89}$ \\ GURGEL, Rafael Lucas da Silva ${ }^{90}$ \\ TEIXEIRA, Glauco Antônio ${ }^{91}$ \\ CAVALLARI, Ludmilla de Lima ${ }^{92}$ \\ RODRIGUES, Helen Cristina de Arruda ${ }^{93}$
}

Recebido em: 2008-06-01

Aprovado em: 2008-09-02

ISSUE DOI: $10.3738 / 1982.2278 .84$

RESUMO: Com o objetivo de avaliar o desenvolvimento de porta-enxertos de uvaia adubados com cloreto de potássio, foi instalado experimento no Setor de Fruticultura da Universidade Federal de Lavras, com quatro doses de cloreto de potássio $\left(0 ; 1,0 ; 2,0 ; 4,0 \mathrm{Kg} \mathrm{m}^{-3}\right)$. Após 90 dias da semeadura, coletaram-se os seguintes dados biométricos: altura média da parte aérea e raíz $(\mathrm{cm})$; número médio de folhas; massa seca média da raiz e da parte aérea $(\mathrm{g})$. Foram encontrados resultados significativos para comprimento da parte aérea comprimento de raiz. $\mathrm{O} \mathrm{KCl}$ promove incremento na produção de mudas de uvaia

Palavras-chave: Eugenia uvalha. Nutrição. Viveiro

\section{POTASSIUM IN THE PRODUCTION OF UVAIA CHANGES}

SUMMARY: With the objective to evaluate the development of uvaia using potassium chloride, this experiment was installed in the Sector of Fruticultura of the Federal University of Lavras, with four doses of potassium chloride $(0 ; 1,0 ; 2,0 ; 4,0 \mathrm{~kg} \mathrm{~m}-3)$. After 90 days of the sowing, the following data had been collected: average height of the aerial part and root $(\mathrm{cm})$; average leaf number; average dry mass of the root and the aerial part (g). They had been found resulted significant for length of the aerial part, length of root. The $\mathrm{KCl}$ promoted good results in production of uvaia changes.

Keywords: Eugenia uvalha. Nutrition. Fishery.

\footnotetext{
${ }^{88}$ Eng. Agrônomo, Mestrando FCAV/Unesp, e-mail: henrique.antuness@yahoo.com.br

${ }^{89}$ Eng. Agrônomo, Prof. Dr. UFERSA, e-mail: vanderm@ufersa.edu.br

${ }^{90}$ Eng. Agrônomo, Mestrando UFLA, e-mail: rafallsgurgel@yahoo.com.br

${ }^{91}$ Eng. Agrônomo, Mestrando UFLA, e-mail: glaucoufla@yahoo.com.br

${ }^{92}$ Eng $^{\text {a }}$. Agrônoma, Mestranda FCAV/Unesp, e-mail: milla.cavallari@pop.com.br

${ }^{93}$ Eng $^{\text {a }}$. Agrônoma, Mestranda UFLA, e-mail: helenarruda@yahoo.com.br
} 


\section{INTRODUÇÃO}

Uvaia é um o arbusto bonito, rústico, de folhas opostas, madeira forte. Na época de floração, as uvaieiras cobrem-se de branco, o fruto é pequeno, oval, amarelo quando maduro; fruto tipo baga, ácido quando imatura e bem doce quando madura; ocorre em Minas Gerais e de São Paulo ao Rio Grande do Sul (SILVA, 1991).

A adubação fosfatada e potássica são importantes no desenvolvimento do estágio inicial da plântula, por isso uma correta adubação deve ser imposta para nutrir de forma correta a muda.

$\mathrm{O}$ fósforo e o potássio ajudam as raízes a as plântulas a se desenvolverem mais rapidamente (aumentando a resistência aos rigores do inverno) e melhora a eficiência do uso da água, favorecendo a resistência a diversas doenças (INSTITUTO DA POTASSA; FOSFATO, 1998).

O potássio é absorvido pelas plantas em grandes quantidades. Para várias espécies, como por exemplo banana, citros, abacaxi e batata, a exigência é muito maior do que para o nitrogênio. Além de sua importância na produção vegetal, é muitas vezes associado à maior resistência das plantas à condições adversas, tais como baixa disponibilidade de água e extremos de temperatura (FURTINI NETO, et al. 2001).

Segundo Oliveira et al. 2003, avaliando genótipos de maracujá e adubação potássica observou-se que houve melhores resultados com a adubação potássica com $640 \mathrm{Kg} / \mathrm{ha}(\mathrm{KCl})$.

Com relação a trabalhos sobre adubação de mudas de uvaia com cloreto de potássio e outros nutrientes, é praticamente inexistente.

Devido à escassez de trabalhos referentes ao sistema de produção de mudas de uvaia com utilização de adubação a base de potássio, realizou-se o presente trabalho com o objetivo de avaliar o desenvolvimento de porta-enxertos de uvaia adubados com cloreto de potássio.

\section{MATERIAL E MÉTODOS}

O presente trabalho foi conduzido no Setor de Fruticultura do Departamento de Agricultura da Universidade Federal de Lavras, Lavras-MG, no primeiro semestre de 2005.

O clima da região é temperado suave (mesotérmico), tipo Cwb. A região está localiza a uma altitude de 913 metros, $21^{\circ} 14^{\prime} 06^{\prime}$ "de latitude e $45^{\circ} 00^{\prime} 00^{\prime \prime}$ de longitude, tem precipitação média anual de 1493,2 mm ocorrendo uma maior concentração entre os meses de 
novembro e fevereiro. Sua temperatura média anual é $19,3{ }^{\circ} \mathrm{C}$ e a umidade relativa do ar é 80\% (CASTRO NETO; SILVEIRA, 1981).

O experimento foi instalado em um telado tipo nylon (50\% de luminosidade). Foram utilizados sacos de polietileno de 2,25 litros, preenchidos com substrato a base de terra, esterco e areia na proporção de 3:2:1 v/v, enriquecidos com quatro diferentes doses de potássio $\left(0 ; 1,0 ; 2,0 ; 4,0 \mathrm{Kg} \mathrm{m}^{-3}\right)$, utilizando-se como fonte de adubo o cloreto de potássio. Foram utilizadas duas sementes de uvaia por saquinho e após o início da emergência, conservou-se apenas um único seedling. $\mathrm{O}$ delineamento experimental utilizado foi em blocos casualizados, com 4 doses de potássio, com cinco repetições e quatro plantas por parcela.

Os tratos culturais utilizados durante o experimento foram irrigação (período da manhã e de tarde), controle de pragas e doenças e retirada de plantas daninhas. Aa adubação de cobertura, via foliar, foi feita quinzenalmente por 3 vezes, sendo iniciada após o desbaste, e foi utilizada como fonte de $\mathrm{N}$, uréia $(0,2 \%)$.

Após 90 dias da semeadura, coletou-se os seguintes dados biométricos: altura média da parte aérea $(\mathrm{cm})$; número médio de folhas; massa seca média da raiz, da parte aérea e total (g).

Os dados foram submetidos à análise de variância pelo teste $\mathrm{F}$ e as médias foram comparadas à análise de regressão, ao nível de 5\% de probabilidade, utilizando-se do Sistema para Análise de Variância - SISVAR (FERREIRA, 2000).

\section{RESULTADOS E DISCUSSÃO}

Verifica-se resultados significativos para as variáveis: comprimento da parte aérea, matéria seca da parte aérea e total. Já para as variáveis comprimento de raiz, número de folhas, e matéria seca de raiz não foram encontrados resultados significativos (Figura 1). 


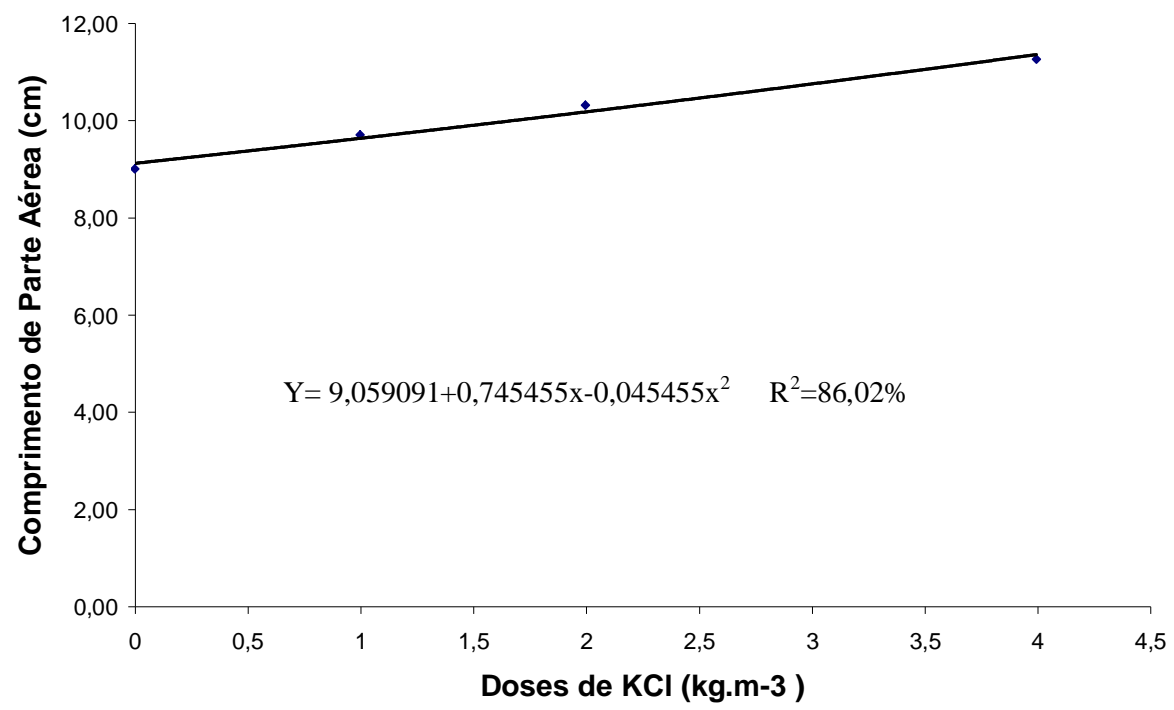

Figura 1. Comprimento da parte aérea de mudas de uvaia em função das doses de $\mathrm{KCL}\left(\mathrm{kg} \cdot \mathrm{m}^{-3}\right)$

A variável altura de mudas teve um comportamento crescente para as doses estudadas, mostrando a eficiência da aplicação do nutriente em incremento para as mudas. Para Gurgel et al. 2004, avaliando a formação de mudas de sapotizeiro, e aplicando fósforo e potássio nas formas de superfosfato simples e cloreto de potássio, observaram uma melhor qualidade com as doses de 5,0 kg.m ${ }^{-3}$ de super simples e 4,0 kg.m ${ }^{-3}$ de $\mathrm{KCl}$ para a formação de mudas.

Já para matéria seca da parte aérea, encontra-se como melhor superfície de resposta a linear crescente, sendo que, à medida que se aumentam as doses, há um incremento no teor de matéria seca da parte aérea.(Figura 2). 


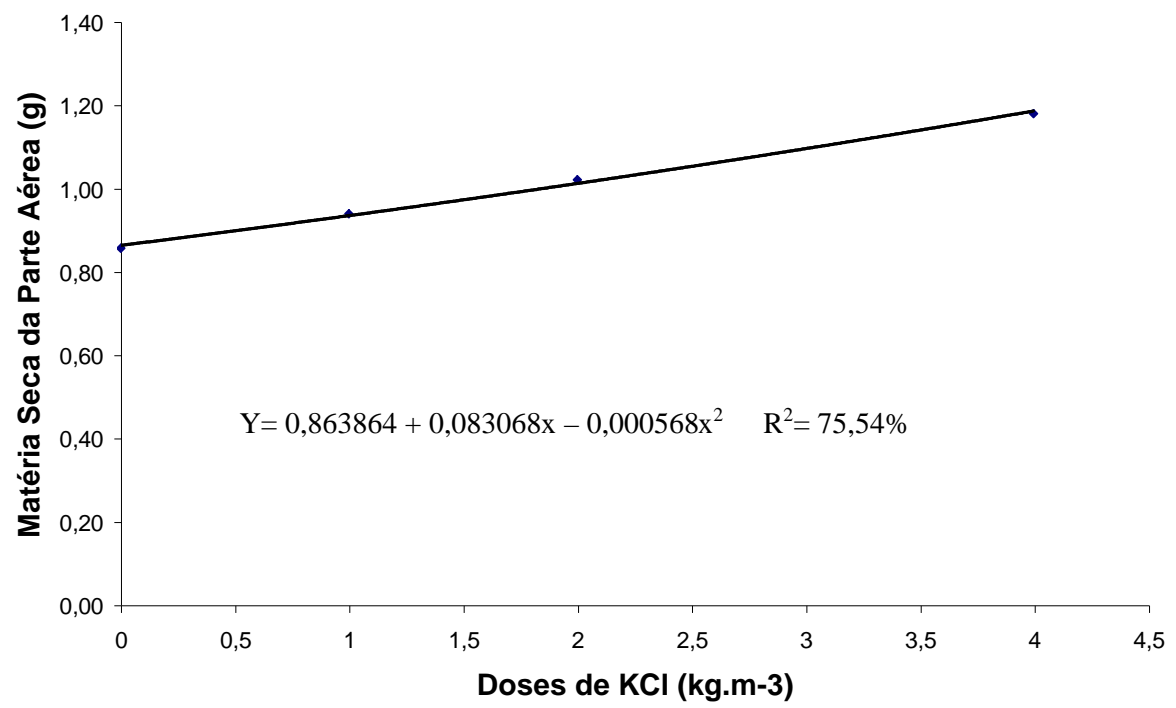

Figura 2. Matéria seca da parte aérea de mudas de uvaia em função das doses de $\mathrm{KCL}\left(\mathrm{kg} \cdot \mathrm{m}^{-3}\right)$

Para matéria seca total, encontramos um valor crescente no ganho de matéria seca à medida que se aumentam as doses, aumenta-se o teor de matéria seca total (Figura 3).

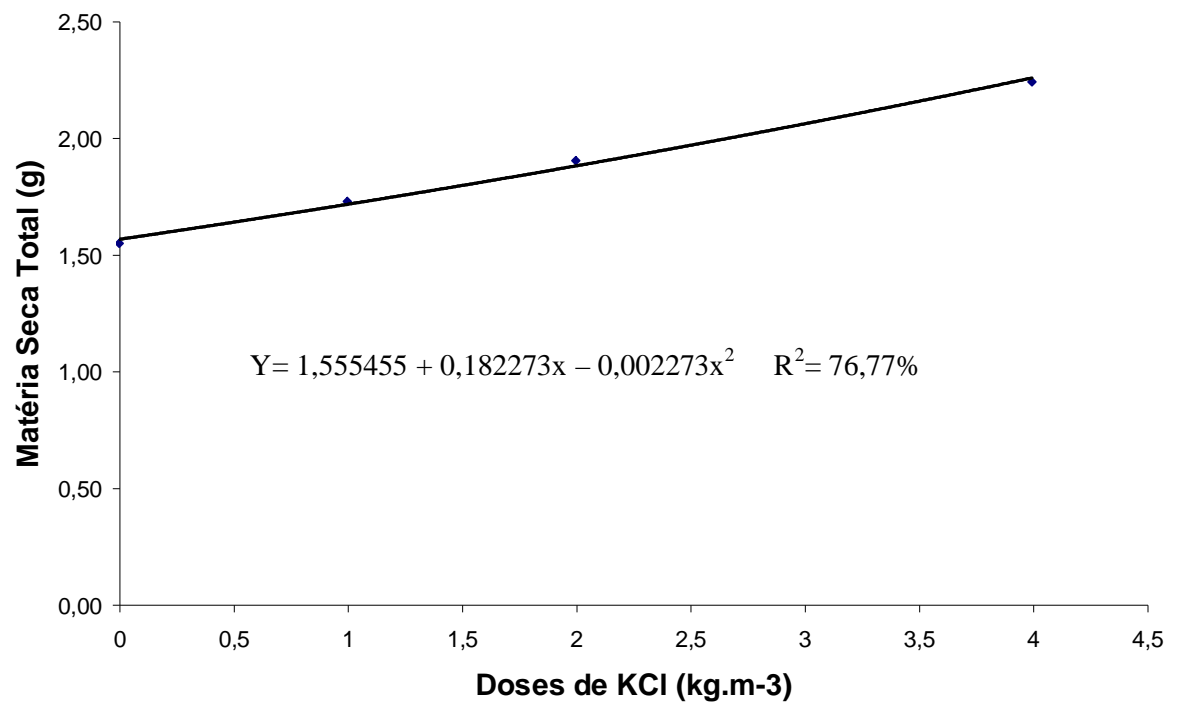

Figura 3. Matéria seca total de mudas de uvaia em função das doses de KCL $\left(\mathrm{kg} \cdot \mathrm{m}^{-3}\right)$

Segundo Prado et al. 2004, objetivou-se avaliar a aplicação de potássio ao substrato de produção de mudas de maracujazeiro-amarelo (Passiflora edulis) e os seus efeitos no 
desenvolvimento, na produção de matéria seca e no estado nutricional das plantas. A maior produção de massa seca das plantas ocorreu na faixa entre 200-220 mg de $\mathrm{K} \mathrm{dm}^{-3}$.

O subsolo, normalmente utilizado para a produção de mudas de espécies frutíferas, apresenta baixa concentração de potássio e, assim, existe grande probabilidade de resposta à aplicação deste nutriente (PRADO et al. 2004). O estudo em questão evidenciou que as mudas foram bem nutridas devido a utilização de substrato com esterco bovino e também com a aplicação do $\mathrm{KCl}$, colaborando com o objetivo deste trabalho, em que podemos afirmar que o nutriente potássio foi favorável às variáveis biométricas, sendo de fundamental importância para a produção de mudas de uvaia, em que esta foi responsiva.

Segundo Boaventura et al. (2004), há perdas de nutrientes, principalmente N e K, por lixiviação, em estudo de balanço de nutrientes em mudas cítricas. Tal fato vêm de encontro com o trabalho que apresentou respostas crescentes de $\mathrm{K}$, mostrando a importância deste nutriente para produção de mudas de fruteiras, incluindo a uvaia. Segundo Teixeira et al. (2001) a adubação potássica favorece a manutenção de folhas ativas. Trabalhos tratando de produção de mudas de uvaia com a aplicação de nutrientes, são incipeintes e necessitam maiores pesquisas, tendo em vista a crescente importância desta fruteira.

\section{CONCLUSÃO}

Para as variáveis comprimento de parte aérea, matéria seca de parte aérea e total, foram encontrados resultados significativos, havendo um incremento no vigor da muda à medida que se aumentava a concentração da dose.

\section{REFERÊNCIAS}

BOAVENTURA, P. R. R. et al. Balanço de nutrientes em mudas cítricas cultivadas em substrato. Rev. Brás. Frutic., v. 26, n. 2, p. 300-305. 2004.

CASTRO NETO, P; SILVEIRA, S. V. Precipitação provável para Lavras, Região Sul de Minas Gerais, baseada na função de distribuição de probabilidade gama. 1 Período mensais. Ciência e Prática, Lavras, v. 5, n. 2, p. 144-151, 1981.

FURTINI NETO, A. E. et al. Fertilidade do solo. UFLA : Lavras, 252 p.

FERREIRA, D. F. Análise estatística por meio do SISVAR (Sistema para Análise de Variância) para Windows versão 4.0. In: REUNIÃO ANUAL DA REGIÃO BRASILEIRA DA SOCIEDADE INTERNACIONAL DE BIOMETRIA, 45., 2000, São Carlos. Anais... São Carlos: UFSCar, 2000. p. 255-258. 
GURGEL, R. L. S. et al. Adubação fosfatada e potássica na formação de mudas porta-enxerto de sapotizeiro. In: CONGRESSO DE INICIAÇÃO CIENTÍFICA DA UFLA (CICESAL), 17, 2004, Lavras. Anais... Lavras : UFLA, 2004. p. 55.

INSTITUTO DA POTASSA \& FOSFATO. Manual internacional de fertilidade do solo. tradução e adaptação de LOPES, A. S., 2.ed. Piracicaba: Potafos, 1998 ; 177p.

OLIVEIRA, A. T. et al. Produtividade de genótipos de maracujazeiro azedo sob doses de potássio. Rev. Brás. Frutic., Jaboticabal, v. 25, n. 3, p. 464-467, 2003.

PRADO, R. M. et al. Aplicação de potássio no estado nutricional e na produção de matéria seca de mudas de maracujazeiro-amarelo. Rev. Brás. Frutic., Jaboticabal, v. 26, n. 2, p. 295 299, 2004.

SILVA, S. P. Uvaia. In: Frutas Brasil Frutas. São Paulo : Empresa das Artes, 1991. p. 162 164.

TEIXEIRA, L. A. J; RUGGIERO, C; NATALE, W. Manutenção de folhas ativas em bananeira-nanicão por meio de manejo de adubações nitrogenadas e potássica e da irrigação. Rev. Brás. Frutic., v. 23, n. 3, p. 699-703. 2001. 
Nucleus, v.5, n.2, out. 2008 